\title{
An inventory for assessment of female workers' health promotion behaviour based on the integrated model of planned behaviour and self-efficacy
}

Z. Keshavarz, ${ }^{7}$ M. Simbar, ${ }^{7}$ A. Ramezankhani ${ }^{2}$ and H.A. Majd ${ }^{3}$

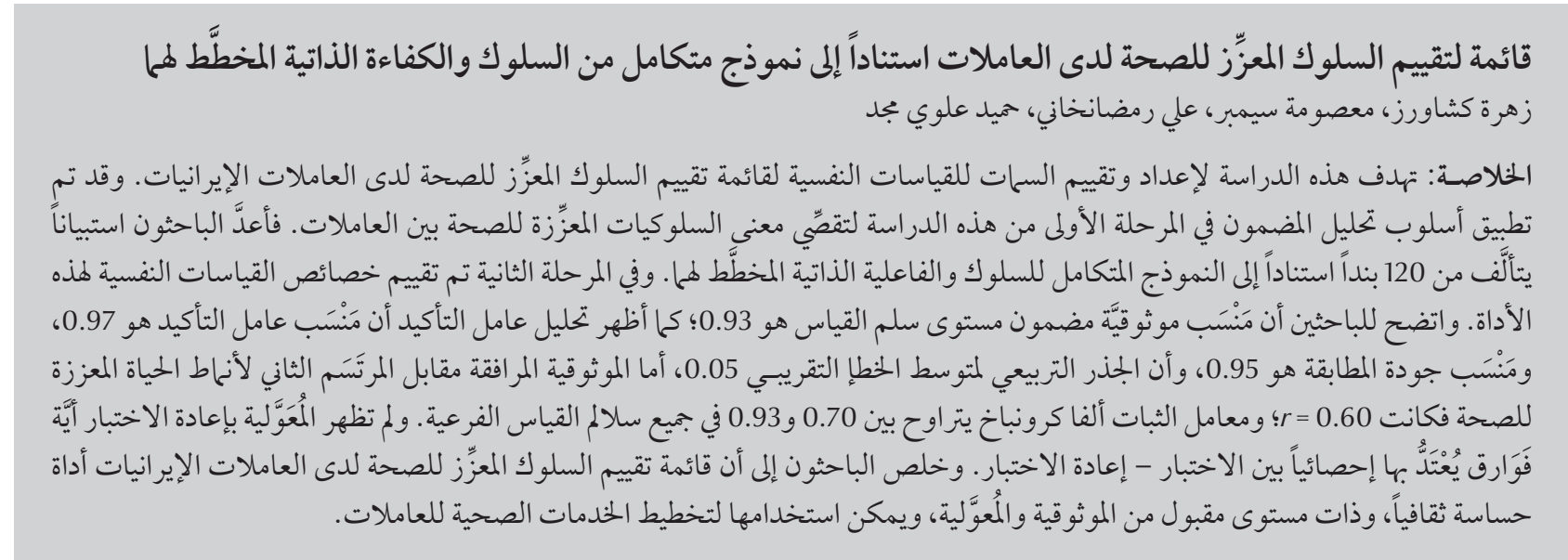

ABSTRACT This study aimed to develop and assess the psychometric properties of an Inventory for Iranian Female Workers' Health Promotion Assessment (IWAHPA). In the first phase of the study a content analysis approach was applied to explore the meaning of health promoting behaviours among female workers. A 120item questionnaire was developed, based on the integrated model of planned behaviour and self-efficacy. In the second phase the instruments' psychometric properties were assessed. Scale level content validity index was 0.93. Confirmatory factor analysis showed confirmatory factor index 0.97 , goodness of fit index 0.95 and root mean square error of approximation 0.05. Concurrent validity versus the Health-Promoting Lifestyle Profile II showed $r=0.60$. Cronbach alpha ranged from 0.70 to 0.93 across the subscales. Test-retest reliability revealed no significant differences. The IWAHPA is a culturally sensitive instrument, with a satisfactory level of validity and reliability, that can be used for planning female workers' health services.

Inventaire d'évaluation des comportements de promotion de la santé chez des femmes actives basé sur le modèle intégré de comportement planifié et d'auto-efficacité

RÉSUMÉ La présente étude visait à développer et évaluer les propriétés psychométriques de l'inventaire des comportements de promotion de la santé chez les femmes actives iranniennes. Pendant la première phase de l'étude, une analyse du contenu a été menée pour explorer la signification des comportements de promotion de la santé chez des femmes actives. Un questionnaire à 120 items a été mis au point à partir du modèle intégré de comportement planifié et d'auto-efficacité. Pendant la deuxième phase, les propriétés psychométriques des instruments ont été évaluées. Un indice de validité de contenu de l'échelle de 0,93 a été obtenu. Une analyse factorielle confirmatoire a révélé un indice factoriel confirmatoire de 0,97, une validité de l'ajustement de 0,95 et une erreur quadratique moyenne de l'approximation de 0,05. Une validité concurrente de $r=0,60$ a été obtenue par rapport au questionnaire Health-Promoting Lifestyle Profile II. Le coefficient alpha de Cronbach était compris entre 0,70 et 0,93 pour les sous-échelles. La fiabilité test-retest n'a pas révélé de différences significatives. Le questionnaire est culturellement adapté, doté d'une validité et d'une fiabilité satisfaisantes et peut être utilisé pour la programmation des services sanitaires dédiés aux femmes actives.

${ }^{7}$ Department of Reproductive Health and Midwifery, Faculty of Nursing and Midwifery; ${ }^{2}$ Faculty of Health; ${ }^{3}$ Faculty of Paramedical Sciences, Shahid Beheshti University of Medical Sciences, Tehran, Islamic Republic of Iran (Correspondence to M. Simbar: msimbar@yahoo.com). Received: 06/02/12; accepted: 29/04/12 


\section{Introduction}

According to the Ottawa Charter for Health Promotion "To reach a state of complete physical, mental and social well-being, an individual or group must be able to identify and to realize aspirations to satisfy needs and to change or cope with the environment" [1]. Health policy-makers in the Islamic Republic of Iran seek culturally appropriate and acceptable health promotion programmes to effect change in the health behaviours of female workers. However, development of such a programme requires an appropriate questionnaire to obtain information about these women's needs. Since health promoting behaviours are related to the social, cultural and economic conditions of communities, the content of such a tool should be culturally appropriate for the community in which the tool is going to be used. A questionnaire for health promotion behaviour assessment developed in one community is a reflection of the same community's culture and language and its use in any other community may not be culturally appropriate and could create issues of validity, even if the translation is precise [2]. Experts in psychometry agree that to ensure the suitability of content and language the items of such a questionnaire should be directly extracted from statements of the target groups.

The theory of planned behaviour makes a useful psychosocial framework for understanding the health behaviour of individuals and designing appropriate educational programmes. According to the model the 3 main factors affecting intention to performing a behaviour are: attitudes, subjective norms and perceived behavioural control. Some researchers believe that adding the concept of self-efficacy to the planned behaviour model can increase the predictability of behaviours by the model [3]. Self-efficacy, which has its root in the social cognitive theory of Bandura, affects behaviour change and therefore plays an important role in the planning of educational programmes [4].

In view of the lack of a valid and reliable questionnaire for assessment of female workers' health promotion behaviour in our country, this study aimed to develop and to assess the psychometric properties of the Inventory for Iranian Female Workers' Health Promotion Assessment (IWAHPA), based on the integrated model of planned behaviour and self-efficacy.

\section{Methods}

\section{Study design}

This was a methodological study using both qualitative and quantitative approaches. It was performed in 2 stages. The first stage was an exploratory study to define the concepts and dimensions of factors affecting female workers' health promoting behaviours. In the second stage of the study, the validity and reliability of the questionnaire were assessed using standard methods. The approval of the ethics committee of Shahid Beheshti University of Medical Sciences was obtained for the study.

\section{Sample}

In line with the objectives of the study, participants were selected using a purposeful sampling method from 20- to 45-year-old healthy female workers who were working in industrial factories of Pakdasht, in the east of Tehran city, between July and March 2010. Female workers were recruited from different age groups, job levels, marital status and educational status to have a maximum diversity in the sample. The sampling process was continued until data saturation occurred.

\section{Instrument development}

In the first phase of the study a content analysis approach was applied to explore the health promoting behaviours of female workers, based on the integrated model of planned behaviour and selfefficacy. Data were obtained on female workers' perspectives in focus group discussions (FGD) and on a detailed literature review by the authors.

A total of 10 FGD with 70 women, in groups of 6 to 8 females, were performed. FGD were conducted in Farsi language by the first author as the facilitator plus a note-taker in the factory counsellor's office in their workplace or in a room in the health centre as they wished. The aims and procedure of the study were explained to the participants and their consent was obtained for recording FGD. The discussions began with a question about health promoting behaviours of female workers and then continued with a few exploratory questions to access deeper information. The average duration of FGD was 60-90 minutes. All the discussions were recorded and notes were taken.

The transcripts were analysed using the content analysis method. Each transcript was re-read several times to gain a feeling of completeness. Codes were extracted from participants' sentences in the transcriptions. These were considered as the meaning units. Then statements were formed from the meaning units, each one demonstrating a health promoting behaviour (nutrition, exercise, breast and cervix screening, coping with stress), based on the integrated model of planned behaviour and self-efficacy. These statements plus other statements, which were extracted from a detailed review of related tools, articles and books on women's healthpromotion behaviours, were used to develop the preliminary Farsi language questionnaire for testing.

\section{Instrument validation}

In the second phase of the study the validity of the questionnaire was assessed using face validity, content validity, construct validity, concurrent validity, internal consistency and test-retest reliability. 


\section{Content validity ratio}

The content validity ratio (CVR) was assessed by 20 faculty members of Iranian universities who were experts in reproductive health, midwifery, obstetrics and gynaecology, health education, nursing, community health and psychology. Lawshe proposed that each of the subject matter expert raters on a judging panel respond to the following question for each item: "Is the skill or knowledge measured by this item 'essential,' 'useful, but not essential' or 'not necessary' to the performance of the construct?" [5]. According to Lawshe, if more than half the panellists indicate that an item is essential, that item has at least some content validity; greater levels of content validity exist as larger numbers of panellists agree that a particular item is essential. Using these assumptions, Lawshe developed the formula CVR $=[n e-N / 2] /[N / 2]$, where ne = number of panellists indicating an item is "essential" and $N=$ total number of panellists [5]. Statements which had CVR $<0.42$ were omitted.

\section{Content validity index}

The content validity index (CVI) was assessed by a different panel of 15 faculty members of Iranian universities. Using Waltz and Bausell's method the experts scored the relevancy, clarity and simplicity of each statement in the questionnaire using a Likert-type scale [6]. The CVI score for each statement was calculated by dividing the number of experts agreeing (i.e. scored 3 and 4 in the Likert scale) by the total number of experts. The statement was accepted if the calculated CVI was $\geq 79 \%[7]$.

\section{Face validity}

To assess face validity, experts and 10 female workers assessed the clarity and fluency of statements and revised some of the items.

\section{Construct validity}

After calculation of internal consistency, the construct validity of the revised instrument was assessed using the confirmatory factor analysis method. Required samples for factor analysis were 10 to 30 samples for each construct of the model. However, 100 to 200 samples could be enough for calculation of the necessary correlation coefficient [8]. Therefore, 200 female workers from industrial factories were recruited for this phase of the study and completed the questionnaire. Confirmatory factor analysis was run using LISREL software, version 8.7. The chi-squared statistic was used to assess model fit [9]. A non-significant chisquared-value indicates strong model fit. The chi-squared statistic, however, can be influenced by sample size and should not be used as a stand-alone measure of model fitness. Other indices such as the confirmatory factor index (CFI), goodness of fit index (GFI) and root mean square error of approximation (RMSEA) were calculated to assess model fit.

\section{Criterion validity}

After assessment of content, face and construct validity of the instrument, the criterion validity (concurrent) of the questionnaire was assessed using the Health-Promoting Lifestyle Profile (HPLP-II). Both the new instrument and the HPLP II were completed concurrently by 100 female workers. The HPLP II, developed by Walker et al., has 52 statements in 6 dimensions (nutrition, physical activity, spiritual growth, health responsibility, stress management and interpersonal relationships) and is scored using a Likerttype scale [10]. This tool has been translated into several languages and its psychometric properties have been assessed in different countries. The psychometric properties of Farsi version of the HPLP II have been assessed by Iranian researchers who showed an acceptable validity and reliability of HPLP II [11-13]. HPLP II was used as the inventory because there is positive correlation between quality of life and health promoting behaviours of people $[14,15]$.

\section{Reliability}

Internal consistency and test-retest reliability methods were used to assess the reliability of the questionnaire [16]. The Cronbach alpha coefficient shows the appropriateness of a group of statements for a construct in a questionnaire. An acceptable coefficient for internal consistency should be $\geq 0.7-0.8$ [17]. To assess the internal consistency of the questionnaire Cronbach alpha coefficient was calculated for each factor and also for whole questionnaire, from the forms completed by 200 female workers.

The stability of the questionnaire was also assessed using the test-retest reliability measurement method [18]. Appropriate time interval for test-retest can be between 2 weeks to 1 month [19]. A subgroup of 20 female workers completed the questionnaire forms twice in a 2-week interval period. Wilcoxon test was used to compare test-retest scores of the questionnaire.

Calculation of Cronbach alpha coefficient and Wilcoxon test were done using SPSS software, version 17.

\section{Results}

\section{Instrument development}

Content analysis with the conventional method of transcriptions of the interviews with female workers demonstrated 6 main themes, including the main constructs of the research model: attitude, subjective norm, perceived behavioural control, self-efficacy, intention and behaviour. Extracted codes and an extensive literature review on women's health were used to draw up the preliminary tool with 180 statements. Then, similar statements were omitted or combined by the researchers in 4 assessment sessions. Subsequently, a questionnaire was developed with 120 statements 
answered using a 5-level Likert-scale (completely disagrees, disagree, no idea, agree and completely agree, scored 1, 2, 3,4 and 5 respectively). Table 1 shows a translated version of the questionnaire items.

\section{Instrument validation}

In the first stage of the validation 4 statements that had CVR $<0.42$ were omitted (items 27, 28, 31, 32) (Table 1). In the next stage statements with CVI < 0.79 were omitted (items 25, 37, 39, 42, 53), which reduced the questionnaire from 116 to 110 statements. The scalelevel content validity index (S-CVI) was 0.93 ; a value $>0.92$ shows an acceptable validity of an instrument [20]. Then researchers attempted to make a correct, reasonable and clear writing of statements based on female workers' and experts' opinion to improve the face validity of the items in the questionnaire.

Confirmatory factor analysis of the revised questionnaire showed that: $\mathrm{CFI}$ $=0.97, \mathrm{GFI}=0.95$, RMSEA $=0.05$, chisquared $=31.84(P=0.016)$. Criterion validity assessment of the instrument demonstrated a correlation between the scores of the developed questionnaire with the scores of the HPLP II $(r$ $=-0.60, P<0.001)$. Cronbach alpha to assess the reliability of the questionnaire demonstrated correlations between 0.70 to 0.93 for the constructs of the instrument, and 0.90 for the whole instrument when 10 statements were omitted. The Wilcoxon test to assess the stability of the questionnaire following test-retest demonstrated no significant differences between the scores of test-retest of the questionnaire $(P$ $>0.05$ ).

Finally, 100 statements remained, in 6 constructs. These constructs were named as: attitude toward behaviour (25 statements), subjective norms (15 statements), perceived behavioural control (14 statements), self-efficacy (19 statements), intention (8 statements) and behaviour (19 statements) including 4 domains of health promoting behaviours such as: nutrition, exercise, breast and cervix screening tests and coping with stress. The total score of each construct was the average of scores of its statements. The total score of the instrument was the average of scores of its constructs. The IWAHPA can be completed in 15 to 20 minutes.

\section{Discussion}

This research is the first study to develop and evaluate the psychometric properties of a tool for assessment of female workers' health promoting behaviour in the Islamic Republic of Iran. The conceptual framework for the study was based on a psychosocial model of planned behaviour and selfefficacy. A preliminary questionnaire was developed from FGD with female workers as well as from a wide review of the related literature. The content validity of the preliminary questionnaire was then assessed by a panel of experts. Content validity assessment of questionnaires by experts is one of the best ways to develop an evidenced-based questionnaire with appropriate content [21]. In a similar study to develop and psychometrically test an adolescent health promotion scale, content validity was considered to be supported based on the findings of previous studies and the observations of a panel of 14 content experts to confirm their developed questionnaires [22].

In the next stage construct validity was assessed using confirmatory factor analysis from questionnaires completed by a sample of 200 workers, as in a similar study to assess an instrument for management support for worksite health promotion [11]. Hu and Bentler recommend evaluating models against the following cut-off values: values below an RMSEA of 0.06, and values above a goodness of fit and CFI of 0.95 [9]. Our results revealed CFI $=0.95$, GFI $=0.90$, RMSEA $=0.05$ and chi-squared $=31.84$ and indicated a strong model fit.
There was also a significant positive correlation $(r=-0.60)$ between women's scores on the IWAHPA and on another tool, the HPLP II, in the assessment of criterion validity. This finding is consistent with results of other studies which demonstrated that there was a positive correlation between health promotion and lifestyles $[14,15]$.

Reliability of a tool also needs to evaluated. A reliable tool increases the ability of a study to demonstrate real differences and relations [19]. The IWAHPA had an acceptable internal consistency and stability. Cronbach alpha reliability coefficient for the whole instrument (with 10 statements omitted) was 0.90 and ranged from 0.70 to 0.93 for individual constructs of the instrument. In a similar study Cronbach alpha was 0.93 , and alpha coefficients for the subscales ranged from 0.75 to 0.88 [22].

\section{Conclusion}

The psychometric properties of the IWAHPA were developed based on perceived concepts of health promoting behaviours by Iranian female workers in factories of a city in the east of Islamic Republic of Iran, using a deep qualitative research and showing an acceptable validity and reliability. A key difference of the IWAHPA from other related tools is that it includes effective factors on performing the main health promoting behaviours such as nutrition, exercise, breast and cervix screening tests and on coping with stress among female workers based on a psychosocial model of integrated model of planned behaviour and self-efficacy. The IWAHPA is the first valid, reliable and culturally appropriate tool developed for assessing female workers' health promotion behaviour. It can be completed in 15 to 20 minutes Assessment of the psychometric properties of the IWAHPA is recommended within other similar countries. 


\begin{tabular}{|c|c|c|c|c|c|}
\hline \multirow[t]{2}{*}{ Item no. } & \multirow[t]{2}{*}{ Statement } & \multirow{2}{*}{$\begin{array}{c}\text { Content } \\
\text { validity ratio }\end{array}$} & \multicolumn{3}{|c|}{ Content validity index } \\
\hline & & & Relevancy & Simplicity & Clarity \\
\hline & I care about the: & & & & \\
\hline 1 & Amount of fat I eat & 1 & 1 & 1 & 1 \\
\hline 2 & Amount of salt I eat & 1 & 1 & 1 & 1 \\
\hline \multirow[t]{2}{*}{3} & Amount of glucose I eat & 1 & 1 & 1 & 1 \\
\hline & I eat every day: & & & & \\
\hline 4 & Fruits and vegetables $2-4$ times & 1 & 1 & 1 & 1 \\
\hline 5 & Dairy (milk, yogurt) & 1 & 1 & 1 & 1 \\
\hline 6 & Meat (fish, eggs) & 1 & 1 & 1 & 1 \\
\hline \multirow[t]{2}{*}{7} & Breakfast & 1 & 1 & 1 & 1 \\
\hline & I exercise: & & & & \\
\hline 8 & At least 3 times each time 20-30 minutes every week & 1 & 0.93 & 0.93 & 1 \\
\hline \multirow[t]{2}{*}{9} & During working hours (e.g. walking, climbing stairs) & 1 & 0.80 & 0.93 & 1 \\
\hline & I do the following: & & & & \\
\hline 10 & Care about my pulse rate during exercise & 1 & 0.93 & 1 & 0.93 \\
\hline 11 & Report any abnormal signs or symptoms to my physician & 0.80 & 0.93 & 0.93 & 1 \\
\hline 12 & Perform cancer screening tests regularly & 0.90 & 0.86 & 0.93 & 0.93 \\
\hline 13 & Seek information about self-care & 0.90 & 1 & 1 & 1 \\
\hline 14 & Feel calm, with trust in God & 1 & 1 & 1 & 1 \\
\hline 15 & Strive for goals through my life & 1 & 0.86 & 0.93 & 1 \\
\hline 16 & Balance work and leisure time & 0.70 & 1 & 1 & 1 \\
\hline 17 & $\begin{array}{l}\text { Use special methods to cope with stress (e.g. walking, } \\
\text { praying) }\end{array}$ & 0.70 & 1 & 1 & 1 \\
\hline 18 & Talk to my family about my problems & 1 & 1 & 1 & 1 \\
\hline \multirow[t]{2}{*}{19} & Show emotions to others easily & 1 & 1 & 1 & 1 \\
\hline & For me having: & & & & \\
\hline 20 & 2 glasses of milk/yogurt is beneficial & 1 & 1 & 1 & 1 \\
\hline 21 & Vegetables twice a day is beneficial & 1 & 1 & 1 & 1 \\
\hline 22 & Fruits twice a day is beneficial & 1 & 1 & 1 & 1 \\
\hline 23 & Sausage/salami is harmless & 0.70 & 0.93 & 1 & 0.93 \\
\hline \multirow[t]{2}{*}{24} & Canned food is harmless & 0.80 & 0.93 & 0.93 & 1 \\
\hline & I believe that: & & & & \\
\hline 25 & Fast foods are healthy diets & 0.60 & 0.46 & 0.93 & 0.86 \\
\hline 26 & $\begin{array}{l}\text { Doing exercise for at least } 3 \text { times each time, } 20 \text { minutes, } \\
\text { is beneficial }\end{array}$ & 0.90 & 0.80 & 0.93 & 1 \\
\hline 27 & Doing exercise is just for women who do not work & 0.40 & - & - & - \\
\hline 28 & Working is the same as exercise & 0.30 & - & - & - \\
\hline 29 & Walking and climbing stairs is the same as exercise & 0.70 & 0.80 & 1 & 1 \\
\hline 30 & Exercise prevents osteoporosis & 0.90 & 1 & 1 & 1 \\
\hline 31 & Walking, swimming, biking are aerobic exercises & 0.40 & - & - & - \\
\hline 32 & Aerobic exercises increase body metabolism & 0.40 & - & - & - \\
\hline 33 & $\begin{array}{l}\text { Visiting doctor/midwife for breast clinical examination is } \\
\text { beneficial }\end{array}$ & 0.70 & 1 & 1 & 1 \\
\hline 34 & Detecting breast masses by mammography is valuable & 0.80 & 1 & 1 & 1 \\
\hline 35 & Regular breast self-examination for all women is beneficial & 1 & 1 & 1 & 1 \\
\hline 36 & Breast cancer is not treatable & 0.50 & 0.60 & 0.93 & 1 \\
\hline 37 & Every mass in the breast is malignant & 0.60 & 0.53 & 0.93 & 1 \\
\hline
\end{tabular}




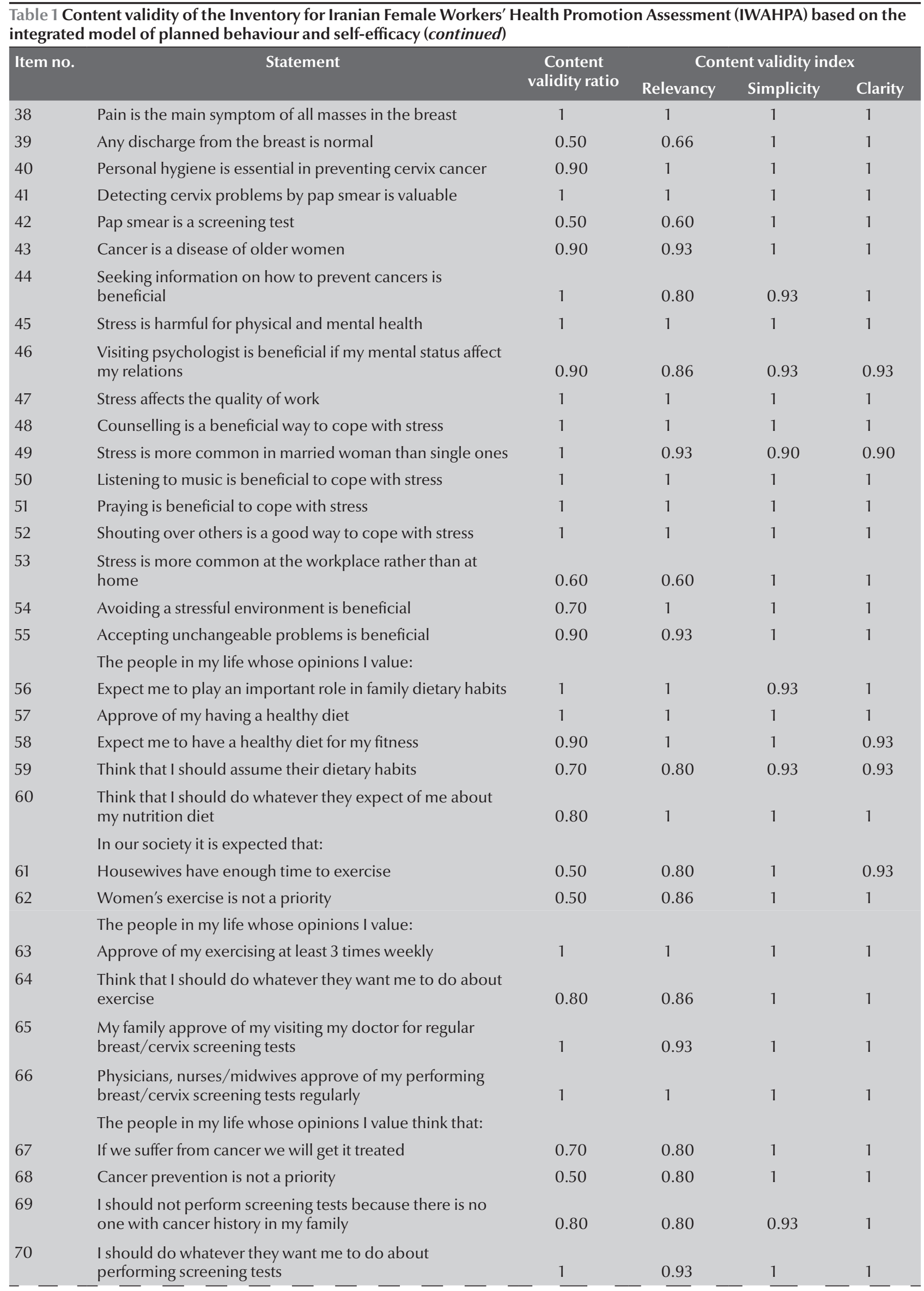




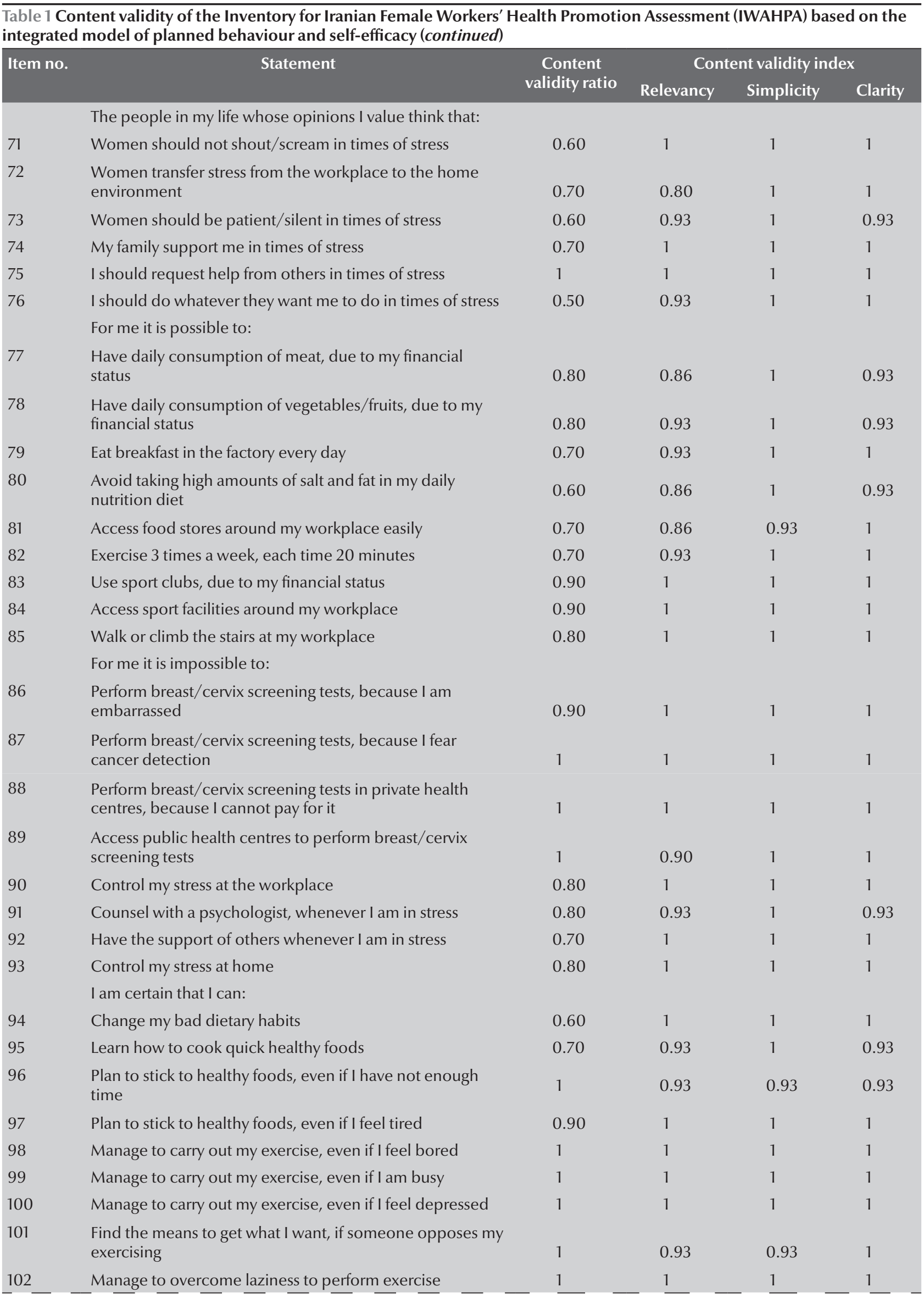




\begin{tabular}{|c|c|c|c|c|c|}
\hline \multirow[t]{2}{*}{ Item no. } & \multirow[t]{2}{*}{ Statement } & \multirow{2}{*}{$\begin{array}{c}\text { Content } \\
\text { validity ratio }\end{array}$} & \multicolumn{3}{|c|}{ Content validity index } \\
\hline & & & Relevancy & Simplicity & Clarity \\
\hline 103 & $\begin{array}{l}\text { Plan to perform breast/cervix screening tests, even if I am } \\
\text { busy }\end{array}$ & 1 & 0.93 & 0.93 & 0.86 \\
\hline 104 & $\begin{array}{l}\text { Plan to perform breast/cervix screening tests, even if I feel } \\
\text { tired }\end{array}$ & 0.90 & 1 & 0.93 & 1 \\
\hline 105 & $\begin{array}{l}\text { Plan to perform breast/cervix screening tests, even if I feel } \\
\text { depressed }\end{array}$ & 0.90 & 0.86 & 0.93 & 0.93 \\
\hline 106 & $\begin{array}{l}\text { Plan to perform breast/cervix screening tests, even if I feel } \\
\text { embarrassed }\end{array}$ & 0.70 & 0.86 & 0.86 & 0.86 \\
\hline 107 & $\begin{array}{l}\text { Find the means to get what I want, if someone opposes me } \\
\text { to perform screening tests }\end{array}$ & 0.80 & 0.93 & 1 & 1 \\
\hline 108 & $\begin{array}{l}\text { Learn the skills of coping with stress, even if it takes a long } \\
\text { time }\end{array}$ & 0.90 & 1 & 0.93 & 1 \\
\hline 109 & Manage to cope with stress, even if I feel tense & 0.80 & 0.93 & 0.93 & 1 \\
\hline 110 & Manage to solve problems, if I try hard enough & 1 & 1 & 1 & 1 \\
\hline 111 & $\begin{array}{l}\text { Change the bad conditions to good ones, even if I have to } \\
\text { try several times }\end{array}$ & 1 & 1 & 1 & 1 \\
\hline 112 & $\begin{array}{l}\text { Manage to overcome my thoughts at the time of stress } \\
\text { In the next month I intend to: }\end{array}$ & 1 & 1 & 0.93 & 1 \\
\hline 113 & Learn how to cook quick healthy foods & 1 & 0.93 & 1 & 1 \\
\hline 114 & Change my bad dietary habits & 1 & 1 & 1 & 1 \\
\hline 115 & Exercise 3 times a week each time 20 minutes & 1 & 0.93 & 1 & 1 \\
\hline 116 & Perform aerobic exercise & 1 & 0.93 & 1 & 0.93 \\
\hline 117 & Perform breast clinical examination & 1 & 0.93 & 1 & 1 \\
\hline 118 & Perform pap smear & 1 & 0.86 & 1 & 1 \\
\hline 119 & Learn skills of coping with stress & 1 & 1 & 1 & 1 \\
\hline 120 & Have counselling with a psychologist/physician & 1 & 0.93 & 1 & 1 \\
\hline Scale-leve & content validity index & & 0.93 & & \\
\hline
\end{tabular}

\section{Acknowledgements}

We thank the female workers with whom this research was conducted.
Funding: We thank the Research Council of Shahid Beheshti University of Medical Sciences, Tehran, Islamic Republic of Iran for supporting this research which formed part of a $\mathrm{PhD}$ dissertation.

Competing interests: None declared.

\section{References}

1. Milestones in health promotion, statements from global conferences. Geneva, World Health Organization, 2009.

2. Doward LC, Meda MD, Tharsen H. Reuirement for quality of life instruments in clinical research. Value in Health, 2004, 7:134-139.

3. Peterson SJ, Berdew T. Middle range theories: application to nursing research. Philadelphia, Lippincott Williams and Wilkins, 2004.

4. Bastable SB. Nurse as educator; principles of teaching and learning for nursing practice, 2nd ed. Philadelphia, Lippincott, 2003.

5. Lawshe $\mathrm{CH}$. A qualitative approach to content validity. Personnel Psychology, 1975, 28:563-575.

6. Waltz C, Bausell RB. Nursing research: design, statistics and computer analysis. Philadelphia, F.A. Davis Company, 1981.
7. Hyrkas K, Schmidlechner KA, Oksa L. Validating an instrument for clinical supervision using an expert panel. International Journal of Nursing Studies, 2003, 40:619-625.

8. Munro BH. Statistical methods for health care research, 4th ed. Philadelphia, Lippincott, Williams and Wilkins, 2005.

9. Hu LT, Bentler PM. Fit indices in covariance structure modeling:sensitivity to underparameterized model misspecification. Psychological Methods, 1998, 3:424-458.

10. Walker SN, Sechrist KR, Pender NJ. The health promoting lifestyle profile : Development and psychometric characteristics. Nursing Research, 1987, 36:76-81.

11. Della LJ et al. Assessing management support for worksite health promotion: psychometric analysis of the leading by 
example instrument. American Journal of Health Promotion, 2008, 22:359-367.

12. Adams $\mathrm{MH}$ et al. Social supports and health promotion lifstyles of rural women. Online Journal of Rural Nursing and Health Care, 2000, 1(1):28-40.

13. Alley $\mathrm{N}$ et al. Health promotion lifstyles of woman experiences crisis. Journal of Community Health Nursing, 1998, 15:91-99.

14. Stuifbergen AK, Seraphine A, Roberts G. An explanatory model of health promotion and quality of life in chronic disease conditions. Nursing Research, 2000, 49:122-129.

15. Wang $\mathrm{D}$ et al. Health promoting lifestyles of university students in Mainland China. BMC Public Health, 2009, 9:379.

16. Dempsey PA, Dempsey AD. Using research: process, critical evaluation and utilization, 5th ed. Philadelphia, Lippincott, 1999.
17. Bland JM, Atman DG. Statistic note: Cronbach alpha. British Medical Journal, 1997, 314:572.

18. Fox DJ. Fundamentals of nursing research, 4th ed. New York, Appleton-Century-Crofts, 2006.

19. Burns N, Grove SK. Understanding nursing research, 2nd ed. Philadelphia, WB Saunders, 2003.

20. Polit DF, Beck CT, Owen SV. Is the CVI an acceptable indicator of content validity? Appraisal and recommendations. Research in Nursing and Health, 2007, 30:459-467.

21. Rubio DM et al. Objectifying content validity: conducting a content validity study in social work research. Social Work Research, 2003, 27:94-104.

22. Chen MY et al. Adolescent health promotion scale: development and psychometric testing. Public Health Nursing, 2003, 20:104-110.

\section{Human resources for health observatory}

Human Resources for Health (HRH) are widely recognized as the key element for scaling up health interventions to achieve national goals and health-related targets of the Millennium Development Goals. The need for better data and information to inform policy development has led to the creation of Human Resources for Health Observatory in the Region. The Observatory collects and analyses data on health workforce for more rational approaches to their development. The Main objectives of the observatory are to:

- collect and synthesize data on the health workforce and health care labour market in the country or Region;

- track and assess the dynamics of the workforce and the labour market to identify changes and trends relevant to policy-making and planning;

- improve the evidence base by conducting new research, policy mapping and analysis, evaluating interventions, forecasting exercises to identify future needs, study the satisfaction and expectations of health workers, cost-policy options, and carry out comparative studies (between occupational groups, subnationally and internationally);

- $\quad$ support, inform and direct policy and planning by identifying policy options; assessing the feasibility of interventions; planning scenarios; disseminating international good practices; and preparing policy briefs;

- $\quad$ improve and strengthen the capacity and understanding of senior policy-makers and planners, technical staff and HRH managers of HRH issues;

- $\quad$ advocate and facilitate policy dialogue between stakeholders.

Further information about the human resources for health observatory can be found at: http://www.emro.who.int/ entity/human-resources-observatory/ 